\section{Hepatic injury following colonoscopy}

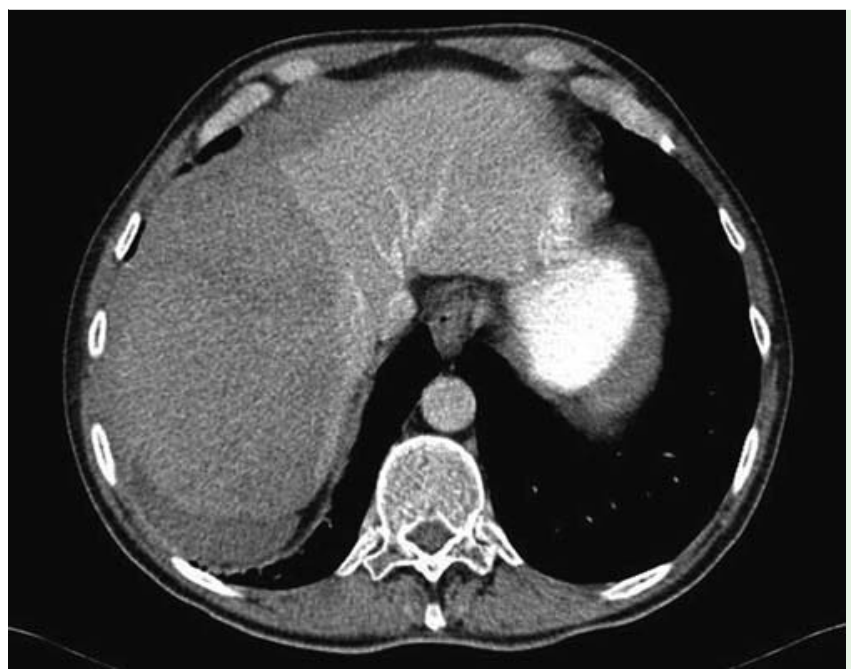

Fig. 1 Abdominal computed tomography showed a right hepatic lobe lesion with hematoma.

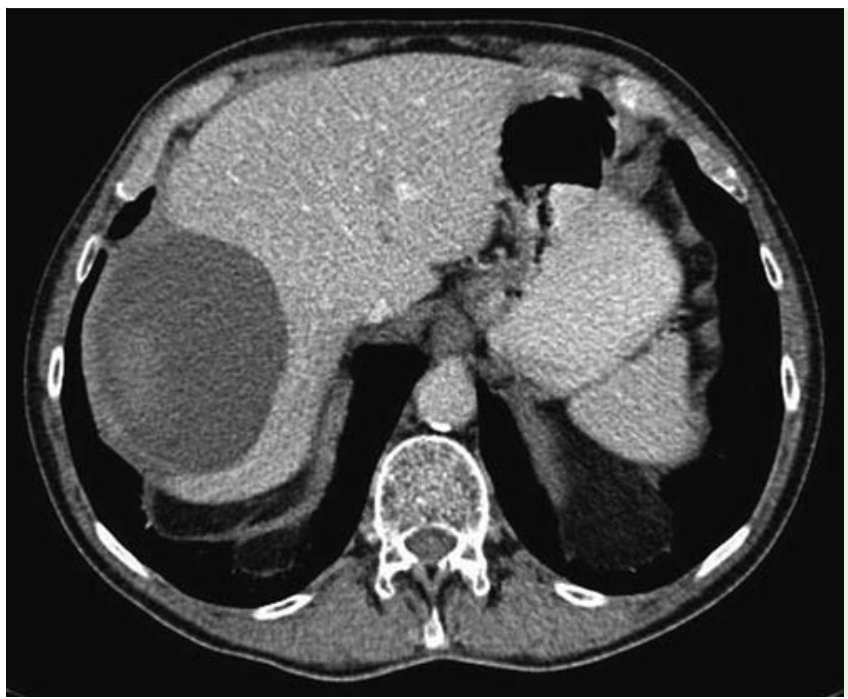

Fig. 2 Follow-up abdominal computed tomography at 2 months showed organization of the hematoma, which was smaller compared with the initial image.

Hepatic injury after colonoscopy is an extremely rare complication, previously described only by Levine and Wetzel in 1987 [6]. Nevertheless, it is feasible and may occur more frequently than suspected.

\title{
Endoscopy_UCTN_Code_CPL_1AJ_2AI
}

Competing interests: None

\section{Noreña ${ }^{1}$, A. Varón ${ }^{2}$, C. Dennis ${ }^{3}$, R. Dennis ${ }^{1}$}

${ }^{1}$ Department of Internal Medicine, Fundación Cardioinfantil, Bogotá, Colombia

${ }^{2}$ Gastroenterology and Hepatology Unit, Fundación Cardioinfantil, Bogotá, Colombia

${ }^{3}$ Vascular and General Surgery, Brookhaven Memorial Hospital, New York, USA

Colonoscopy is a common and relatively safe diagnostic and therapeutic procedure. Iatrogenic injuries have been reported in the medical literature, but the overall risk of serious complications such as perforations and visceral lacerations is low [1-4]. Database studies have shown the total complication rate to be in the range of 2.8 per 1000 colonoscopies, with a mortality rate of $0.007 \%$ [5].

A 73-year-old male presented to our Emergency Department 4 days after undergoing a routine diagnostic colonoscopy. The patient complained of increasingly severe right upper quadrant abdominal pain radiating to the ipsilateral lumbar region, and associated with diffuse abdominal tenderness on palpation, but he was hemodynamically stable. An urgent abdominal computed tomography (CT) scan was obtained, which showed a subcapsular hepatic hematoma and a right hepatic lobe laceration as well as a large hemoperitoneum, with no other hepatic parenchymal lesions ( Fig.1). The consultant surgeon performed laparoscopic evaluation and drainage of approximately $1100 \mathrm{~mL}$ of blood without complications. The patient was discharged in a satisfactory condition. A follow-up CT scan 2 months later demonstrated increasing resolution of the hepatic hematoma ( $\bullet$ Fig. 2 ). An abdominal magnetic resonance scan almost a year later showed only a small residual hematoma and confirmed the absence of associated parenchymal lesions.

\section{References}

1 Ko C, Dominitz J. Complications of colonoscopy: magnitude and management. Gastrointest Endosc Clin N Am 2010; 20: 659-671

2 Lalor P, Mann B. Splenic rupture after colonoscopy. J Soc Laparoendosc Surg 2007; 11 : $151-156$

3 Tse C, Chung K, Hwang J. Splenic injury following colonoscopy. Hong Kong Med J 1999; 5: 202-203

4 Prowda J, Trevisan S, Lev-Toaff A. Splenic injury after colonoscopy: conservative management using CT. Am J Roentgenol 2005; 185: $708-710$

5 Casanova Martínez L, Martín Arranz E, Vázquez López $P$ et al. [Splenic rupture after colonoscopy. An unusual complication] [Article in Spanish]. Gastroenterol Hepatol 2011; 34: 588-589

6 Levine E, Wetzel L. Splenic trauma during colonoscopy. Am J Roentgenol 1987; 149: 939-940

\section{Bibliography}

DOI http://dx.doi.org/

10.1055/s-0033-1344354

Endoscopy 2013; 45: E247

(C) Georg Thieme Verlag KG

Stuttgart · New York

ISSN 0013-726X

\section{Corresponding author}

\section{R. Dennis, MD, FACP}

Department of Internal Medicine

Fundación Cardioinfantil

Cll 163A №13B-60

Bogotá 102973

Colombia

Fax: +57-1-6672727

rdennis@cardioinfantil.org 